\title{
O Fortalecimento da Cidadania como Estratégia de Design para Prevenção de Crimes
}

\section{Citizenship Strengthening as a Design Strategy for Crime Prevention}

\author{
Mariana Rosa de Almeida \\ Graduanda em Design Gráfico na Escola de Design da Universidade do Estado de Minas Gerais (ED-UEMG) - \\ almarirosa@gmail.com - orcid.org/0000-0001-5858-4756 \\ Suéllen Mota Marques Costa \\ Mestre em Construção Civil pela Escola de Engenharia da Universidade Federal de Minas Gerais (UFMG)- \\ suellenmc@hotmail.com - orcid.org/0000-0001-9244-4706 \\ Rita de Castro Engler \\ Doutora em Engenharia de Produção e Gestão de Inovação Tecnológica pela Ecole Centrale Paris - \\ rita.engler@gmail.com - orcid.org/0000-0002-5707-2924
}

\begin{abstract}
Resumo
Além da ação policial, outros fatores contribuem para a prevenção do crime, dentre eles, o design. A abordagem Crime Prevention Through Environmental Design (CPTED) utiliza o design para modificar a percepção do transgressor quanto à oportunidade e o benefício do crime. O objetivo da pesquisa consistiu em identificar no Parque do Confisco (município de Belo Horizonte, estado de Minas Gerais, Brasil), sob a ótica do CPTED, fatores que favoreceriam a prática criminosa, bem como verificar a possibilidade de supressão desses fatores. Para tanto, elaborou-se pesquisa bibliográfica e observação espacial em campo. A análise dos dados teve como base as três estratégias do CPTED: controle natural de acesso, vigilância natural e reforço territorial, bem como considerou alguns aspectos da abordagem 3D (Designação, Definição e Design), típica do CPTED. Os resultados revelaram que a baixa visibilidade, a depredação e a manutenção precária são os principais aspectos que favorecem a prática criminosa no local. É possível implantar melhorias, porém, faz-se necessária a construção de projetos integrados que considerem tanto as dimensões físicas quanto as comportamentais.
\end{abstract}

Palavras-chave: Arte - Proteção. Desenho (Projetos). Parques urbanos. Prevenção de crimes. Meio ambiente (Arte).

\section{Abstract}

In addition to police action, other factors contribute to crime prevention, including design. The Crime Prevention through Environmental Design (CPTED) approach uses design to modify the offender's perception of the opportunity and benefits of crime. The goal of the research was to identify in Parque do Confisco (Belo Horizonte, Minas Gerais, Brazil), based on CPTED, factors that would stimulate criminal practice, as well as to verify if it would be possible to eliminate these factors. To this end, bibliographic research and spatial observation in the field were carried out. The analysis was based on the three strategies of CPTED: natural access control, natural surveillance and territorial reinforcement, as well as the investigation considered some aspects of the 3D approach (Designation, Definition and Design), typical of CPTED. The results revealed that low visibility, depredation and poor maintenance are the main aspects that stimulate criminal practice in the area. It is possible to implement improvements, however, it is necessary to build integrated projects that consider both physical and behavioral dimensions.

Keywords: Art - Protection. Design. Urban parks. Crime prevention. Environment (Art).

Recebido em: 26/06/2020

Aceito em: 27/02/2021 


\title{
1 INTRODUÇÃO
}

Ao contrário do que estabelece o senso comum, a prevenção do crime não se restringe à repressão policial, isto é, não se trata de mero "caso de polícia".

\begin{abstract}
A primeira coisa que deve ficar clara é que a ordem pública - a paz nas calçadas e nas ruas não é mantida basicamente pela polícia, sem com isso negar sua necessidade. É mantida fundamentalmente pela rede intrincada, quase inconsciente, de controles e padrões de comportamento espontâneos presentes em meio ao próprio povo e por ele aplicados. (...) Força policial alguma consegue manter a civilidade onde o cumprimento normal e corriqueiro da lei foi rompido (JACOBS, 2011, p.32, grifo nosso).
\end{abstract}

Logo, existem diversos fatores que interferem na prática criminosa. No cenário internacional contemporâneo, merecem destaque os trabalhos do criminologista britânico Ronald Victor Gemuseus Clarke, pesquisador que há várias décadas estuda a relação entre crime e oportunidade. Segundo Mcclain (2014), Dr. Clarke, professor na Escola de Justiça Criminal da Rutgers University, recebeu o que é considerado o prêmio máximo da criminologia, o Stockholm Prize in Criminology. O prestígio de Clarke na criminologia também é ressaltado por Tilley e Farrell (2012), que dedicam um livro a ele, o qual é nomeado The Reasoning Criminologist: Essays in Honour of Ronald V. Clarke.

Em uma de suas publicações recentes, Clarke (2018) sugere um novo modelo para o estudo do crime, o qual introduziria mudanças no âmbito do design e do gerenciamento, de modo a alterar redes de oportunidades para o crime. Dessa forma, o autor espera modificar o comportamento dos potenciais delinquentes, contribuindo, dessa maneira, para a prevenção do crime.

Da relação entre crime, oportunidade e design surgiu o Crime Prevention Through Environmental Design (CPTED). Segundo Crowe (2013), CPTED estabelece que o ambiente físico pode ser manipulado para produzir efeitos comportamentais capazes de reduzir a incidência e o medo do crime, melhorando a qualidade de vida da população.

Ademais, o CPTED está longe de ser assunto do passado. Atualmente, nos Estados Unidos, o Nacional Institute of Crime Prevention, oferece cursos sobre o CPTED (NATIONAL Institute Of Crime Prevention, 2021). Segundo Perry (2013), enquanto foi diretor do referido instituto, Crowe iniciou um programa de treinamento baseado no CPTED, beneficiando milhares de estudantes.

Embora o CPTED seja estudado nos países de língua inglesa há cerca de meio século, no Brasil, as primeiras publicações sobre o tema apareceram somente no início do século 21. Em 2005, Marco Antônio Amaro lançou o livro intitulado Arquitetura Contra o Crime: Prevenção do Crime Através da Arquitetura Ambiental. Em 2007, Roberson Luiz Bondaruk lançou A Prevenção do Crime 
Através do Desenho Urbano. Embora sejam os trabalhos mais relevantes na língua portuguesa do Brasil, há que se considerar que ambos os autores procedem de carreiras militares e, portanto, não tem formação específica em design.

De fato, o CPTED é mais difundido no segmento militar do que propriamente nas escolas de design brasileiras. Encontram-se diversos artigos sobre o assunto na Revista Ordem Pública e Defesa Social (2008-), vinculada à Associação dos Oficiais Militares de Santa Catarina, porém é raro encontrar trabalhos em revistas científicas voltadas para os cursos de design. Dentre as publicações mais recentes na revista, pode-se citar os artigos de Napoleão Júnior e Silveira (2018), Lima Neto e Vieira (2014) e Ferreira, Damázio e Aguiar (2011).

Cabe aos designers gerar alternativas para solução dos problemas sociais do Brasil, sendo um deles a criminalidade. Portanto, o Crime Prevention Through Environmental Design precisa ser divulgado no âmbito acadêmico, de modo a contribuir com a formação dos designers para enfrentamento dessa importante questão.

Haja vista a importância social do CPTED para o design brasileiro, convém elaborar a seguinte pergunta-problema: considerando um ambiente real do país, quais seriam os fatores favoráveis à prática criminosa, sob a ótica do CPTED? Nesse sentido, seria verdadeira a hipótese de que tais fatores poderiam ser removidos, no todo ou em parte, considerando o contexto local?

Logo, este trabalho dedicou-se ao estudo do Parque do Confisco, situado no município de Belo Horizonte, estado de Minas Gerais, Brasil. Tal escolha justifica-se pelos baixos índices de segurança pública apresentados pela região na qual se insere a capital.

A FUNDAÇÃO JOÃO PINHEIRO (2019), divulga regularmente o subíndice IMRS-Segurança Pública, que integra o Índice Mineiro de Responsabilidade Social (IMRS). Este subíndice é calculado por regiões (grupos de munícipios próximos) e considera três fatores: a taxa de homicídios intencionais (número de registros de homicídio doloso por cem mil habitantes); a taxa de crimes violentos contra o patrimônio (número de registros de roubo consumado e de extorsão mediante sequestro consumado por cem mil habitantes) e o número de habitantes por policiais (civis e militares). O IMRS-Segurança Pública 2016 (o qual é uma média dos indicadores de 2015, 2016 e 2017) revelou que a região de Belo Horizonte é uma das que apresenta piores resultados, isto é, baixos valores de segurança pública em relação a outras regiões do estado. 
A seu turno, Amorim (2018) apresenta um mapa com a classificação de regiões de Belo Horizonte conforme as médias anuais de registros de crimes contra o patrimônio durante os anos de 2007 a 2018. A análise do mapa revelou que o Parque do Confisco está situado em região com valores medianos. Tal área foi escolhida por entender-se que o CPTED seria mais eficiente em regiões com taxas de criminalidade intermediárias. Se por um lado as áreas com baixas médias anuais desses crimes não demandam intervenção, por outro lado, áreas com altos valores pressupõem a existência de redes de crime organizado, as quais requerem ações mais complexas para reduzir a ocorrência dos delitos.

O objetivo da pesquisa consistiu em identificar no objeto de estudo, sob a ótica do CPTED, fatores que favoreceriam a prática criminosa, bem como verificar a possibilidade de supressão desses fatores, com vista a melhorar a qualidade de vida dos usuários. Por sua vez, o método consistiu em revisão bibliográfica e observação direta do espaço físico.

A relevância desta pesquisa consiste em sua capacidade de estimular trabalhos futuros. Neste texto, o(a) leitor(a) terá contato com uma análise espacial prévia, baseada no CPTED, bem como compreenderá as relações espaço-usuário envolvidas na aplicação dos conceitos.

\section{A PREVENÇÃO DE CRIMES POR MEIO DO DESIGN DE AMBIENTES}

Segundo Clarke (2018), o positivismo é o principal paradigma utilizado pelos criminologistas. De forma sucinta, tal linha de pensamento define que o comportamento criminoso é determinado pelo passado do delinquente. Consequentemente, questões situacionais e oportunidades favoráveis ao crime são aspectos relegados a segundo plano pelo positivismo.

Contudo, a crítica ao pensamento positivista não se restringe à criminologia. Por exemplo, o positivismo visa explicar o sucesso pessoal na ampla gama do esforço individual. Tal ideia abarcaria a educação dos filhos; a ciência; as artes; os negócios, etc. Além disso, o sucesso nessas áreas dependeria parcialmente do passado individual, a saber, a herança genética, a classe social, a educação familiar e escolar. Todavia, a crítica ao pensamento positivista pondera a necessidade de considerar os efeitos da casualidade: estar no lugar certo, na hora certa; conhecer pessoas específicas; descoberta de oportunidades específicas e outras tantas circunstâncias que desempenham um importante papel na vida cotidiana (CLARKE, 2018). 
Portanto, Ronald Clake propôs a Prevenção Situacional do Delito. Em detrimento do foco no delinquente, Clarke destaca a geração de oportunidades, isto é, a existência de um contexto propício à ocorrência de crimes (CLARKE, 2018). Clarke (1997) afirma que a Prevenção Situacional do Delito procede de uma análise das circunstâncias, as quais originam crimes específicos. Tal estudo pode possibilitar gerenciamento discreto e alterações ambientais no intuito de reduzir as oportunidades para o crime.

Desde a década de 1980, Clarke evidencia a importância de uma nova abordagem para enfrentamento do crime. A maioria das teorias criminológicas dedicam-se ao estudo das razões de certos grupos sociais, expostos a estímulos sociais e psicológicos específicos, estarem frequentemente envolvidos na prática de crimes. Contudo, a ocorrência de um delito não requer apenas a presença de um potencial infrator: a existência de oportunidade para o crime é fundamental (CLARKE, 1997).

Seguindo a mesma linha da Prevenção Situacional do Delito, surgiu o Crime Prevention Through Environmental Design (CPTED). Segundo Perry (2013), o termo foi cunhado por C. Ray Jeffery em 1971, sendo Timothy D. Crowe um dos principais desenvolvedores do conceito. Em 1991, Crowe lançou o livro Crime Prevention Through Environmental Design, o qual contribuiu para melhor entendimento da relação entre design e comportamento humano.

A ideia central do CPTED é a possibilidade de manipulação de ambientes de modo a produzir efeitos comportamentais capazes de reduzir a incidência e o medo do crime, melhorando, dessa forma, a qualidade de vida dos usuários (CROWE, 2013).

A capacidade de influência do ambiente sobre o comportamento humano também é conhecida pelos estudiosos da psicologia ambiental. Campos-de-Carvalho, Cavalcante e Nóbrega (2011) afirmam que, para a psicologia ambiental, ambiente é um conceito que abarca o meio físico (natural ou construído) o qual é inseparável das condições sociais, econômicas, políticas, culturais e psicológicas daquele contexto específico. Por sua vez, Kuhnen e Higuchi (2011, p.250) afirmam que “a percepção ambiental está relacionada ao modo como as pessoas experienciam os aspectos ambientais e seu entorno". "Graças à sua função de interpretação e de construção de significados, a percepção ambiental exerce papel fundamental nos processos de apropriação e de identificação dos espaços e dos ambientes" (KUHEN e HIGUCHI, 2011, p.250). A seu turno, Lynch (1999, p.159) 
afirma que " um ambiente que contenha uma quantidade imensa de estímulos visíveis pode inibir ou provocar certas atividades práticas".

Portanto, para a devida manipulação do ambiente com vistas à alteração do comportamento humano o CPTED lança mão de três estratégias fundamentais que se interpenetram: o controle natural de acesso; a vigilância natural e o reforço territorial (CROWE, 2013).

O controle de acesso consiste em negar acesso de potenciais delinquentes aos possíveis alvos, bem como em criar uma percepção de risco para o provável infrator. Além disso, ele ser mecânico (fechaduras), organizado (profissionais de segurança), ou natural (definição espacial) (CROWE, 2013).

A seu turno, a percepção de risco leva ao conceito de vigilância, que consiste em manter intrusos sob observação. Portanto, uma importante estratégia de vigilância implica em facilitar a observação. Analogamente ao controle de acesso, a vigilância pode ser mecânica (iluminação), organizada (patrulha policial) ou natural (janelas) (CROWE, 2013).

Tanto para o controle de acesso quanto para a vigilância, o termo natural refere-se a um subproduto do uso normal e rotineiro do ambiente. Logo, é possível adaptar o uso corriqueiro de um espaço para produzir em termos de segurança o mesmo efeito das estratégias mecânicas (CROWE, 2013).

A segurança das ruas é mais eficaz, mais informal e envolve menos traços de hostilidade e desconfiança exatamente quando as pessoas as utilizam e usufruem espontaneamente e estão menos conscientes, de maneira geral, de que estão policiando (JACOBS, 2011, p.34).

Por sua vez, o senso de territorialidade implica responsabilidade das pessoas sobre os ambientes que utilizam. Nesse sentido, o design de ambientes pode criar ou ampliar a esfera de influência dos usuários, de modo a desenvolver a noção de propriedade (CROWE, 2013).

Segundo Bondaruk (2007), o abandono de uma praça pela comunidade caminha lado a lado com o abandono da mesma pelo poder público e vice-versa. Como consequência, os delinquentes passam a ocupá-la, determinando ali seu território. Logo, as praças precisam ser atraentes para a população, de modo a criar vínculos de afetividade e pertencimento entre o espaço e a comunidade.

Desde a simples limpeza e conservação da praça [...] até a questão da iluminação, bem posicionada (abaixo dos galhos de arborização, por exemplo [...]) e abundante, tudo deve 
dar aos passantes e usuários dela, uma sensação de conforto e acolhimento (BONDARUK, 2007, p. 230).

As três estratégias do CPTED acarretam o fortalecimento da cidadania, uma vez que reconhecem o papel ativo dos usuários na prevenção de crimes. Contudo, cabe observar que, da mesma forma que evitar jogar lixo em espaços públicos não dispensa o serviço de limpeza, a vigilância natural não prescinde da polícia. Porém, é preciso compreender e destacar que a população também deve fazer a sua parte, observando e cuidando dos espaços que utiliza.

No tocante ao cuidado, Crowe (2013) menciona a importância da manutenção dos espaços, pois, a deterioração e a ferrugem indicam falta de importância e de controle do ambiente para e pelos usuários. Consequentemente, esses locais transmitem aos potenciais delinquentes a mensagem de que ali existe uma alta tolerância para a desordem. A manutenção adequada dos espaços é benéfica para a saúde pública, para a segurança e para o bem-estar, sendo também responsabilidade dos usuários.

Portanto, evitar a utilização de um espaço por delinquentes requer, dentre outras medidas, reduzir a desordem percebida, isto é, a imagem de abandono e falta de manutenção que um determinado espaço transmite às pessoas (LIMA NETO e VIEIRA, 2014). Nesse sentido, Bondaruk (2007) destaca a pichação como um dos elementos que conferem a imagem de decadência a um local.

Sobre o desenho urbano, mais especificamente sobre as calçadas no Brasil, Bondaruk (2007) ressalta a importância de projetos que visem não apenas a manutenção, como também a construção e reestruturação das calçadas. Segundo o autor, as calçadas devem ser convidativas para as pessoas que fazem aquele percurso, de modo que, pela presença delas, a vigilância natural seja estimulada.

Além do cometimento de crimes propriamente dito, faz-se necessário reduzir também o medo do crime. Bondaruk (2007) afirma que o sentimento de insegurança afeta não apenas as pessoas vitimizadas, mas todas aquelas que se sentem vulneráveis à ação criminosa. A sensação de insegurança gera a retração da população, que passa a evitar os espaços públicos, colaborando para o abandono dessas áreas. "Essa retração é um dos grandes problemas de segurança pública no Brasil, pois o delinquente assumirá o controle destes espaços muito mais facilmente (BONDARUK, 2007, p.63). 
A seu turno, Jacobs (2011) menciona a importância da iluminação dos espaços públicos, como estratégia para a prevenção de crimes. A autora afirma que a iluminação adequada das calçadas aumenta o conforto das pessoas. Além disso, "as luzes induzem as pessoas a contribuir com os seus olhos para a manutenção da rua" (JACOBS, 2011, p. 43). No entanto, a autora vai além ao mencionar um importante aspecto correlato ao fortalecimento da cidadania.

\begin{abstract}
Porém, as luzes não têm efeito algum se não houver olhos e não existir cérebro por trás dos olhos, a quase inconsciente reconfirmação de apoio geral da rua para a preservação da civilidade. Quando não há olhos atentos, podem ocorrer crimes horrorosos em público e ocorrem, nas bem iluminadas estações de metrô. Quase nunca ocorrem crimes em salas de espetáculo escuras, onde muitas pessoas e muitos olhos estão presentes" (JACOBS, 2011, p.43, grifo nosso).
\end{abstract}

A importância da atuação da comunidade também é mencionada por Bondaruk (2007), reforçando a ideia de que todos devem fazer a sua parte para a manutenção da segurança nos espaços públicos.

Pessoas ocupando o espaço público, tomando conta dele, preocupadas em melhorar suas condições, vigiando, coibindo e combatendo atitudes anti-sociais, são promotoras mais efetivas de segurança, do que uma viatura policial patrulhando o local (BONDARUK, 2007, p. 39).

\title{
3 MÉTODOS
}

Em conformidade com Gil (2002), esta pesquisa foi classificada como exploratória e delineada como estudo de caso. Tal abordagem foi escolhida por acreditar-se que análise do exemplo pode estimular a compreensão dos princípios do CPTED, destacando a relação entre a prevenção do crime e o design de ambientes. Segundo Gil (2002, p.55), o propósito do estudo de caso consiste em "proporcionar uma visão global do problema ou de identificar possíveis fatores que influenciam ou são influenciados por ele". O autor também menciona o delineamento na modalidade estudo de caso como tradicionalmente empregado em pesquisas de caráter exploratório.

Os métodos escolhidos foram pesquisa bibliográfica e observação direta do espaço físico. Convém notar, que o levantamento de dados em campo foi realizado no ano de 2019, isto é, antes do isolamento social imposto pelos órgãos governamentais de saúde pública como medida indispensável à contenção da pandemia de COVID-19. O trabalho de campo teve como norteadores as três estratégias do CPTED, a saber: controle natural de acesso, vigilância natural e reforço territorial. Foram coletados dados acerca das redes de caminhos de pedestres, equipamentos 
(quadras para práticas de esportes, por exemplo), mobiliário urbano de iluminação artificial e projeto paisagístico (aqui entendido como a configuração das espécies vegetais).

Considerou-se como indicador de precário controle natural de acesso a existência de depredação, pois transmite ao potencial delinquente a mensagem de alta tolerância à desordem naquele local. Por exemplo, um muro pichado informa que um infrator não foi impedido de atuar no local ou seja, teve livre acesso ao alvo (no caso, o muro).

Para estudo das condições de vigilância natural registraram-se os pontos de observação (visadas); as áreas de passagem; a configuração da vegetação; as condições de iluminação natural e artificial.

A seu turno, foram considerados indicadores da baixa apropriação territorial a presença de lixo em local inadequado, bem como a deficiência ou ausência de manutenção. Entende-se que o sentimento de responsabilidade sobre um espaço resulta em zelo com o mesmo, seja evitando sua degradação, seja buscado mecanismos para reparar seu desgaste natural.

Para a análise dos dados coletados, foram elaboradas questões em consonância com a abordagem 3D proposta por Crowe (2013). Segundo o autor, deve-se considerar a designação, a definição e o design. A designação pode ser interpretada e resumida como o uso proposto; a definição, como os limites e os significados do ambiente e o design, como a configuração espacial. Nesse sentido, empregaram-se as seguintes perguntas:

- Qual foi o uso inicialmente proposto?

- Está claro a quem pertence o espaço?

- O design sustenta a função desejada?

Consequentemente, o método resultou em um importante panorama do Parque do Confisco sob a ótica do CPTED. Tal panorama é coerente com a modalidade de pesquisa exploratória, favorecendo subsídios fundamentais para o desenvolvimento de estudos mais profundos no âmbito da prevenção do crime por meio do emprego do design de ambientes. 


\section{CARACTERIZAÇÃO DO OBJETO DE ESTUDO}

O Parque do Confisco, situa-se no Bairro do Conjunto Confisco, no município de Belo Horizonte, estado de Minas Gerais, Brasil (Figura 1). Sua área é de aproximadamente 28 mil metros quadrados e dispõe de equipamentos de lazer para a comunidade (Figura 2) (PREFEITURA MUNICIPAL DE BELO HORIZONTE, 2019).

Figura 1 - Foto aérea com delimitação do Parque do Confisco.

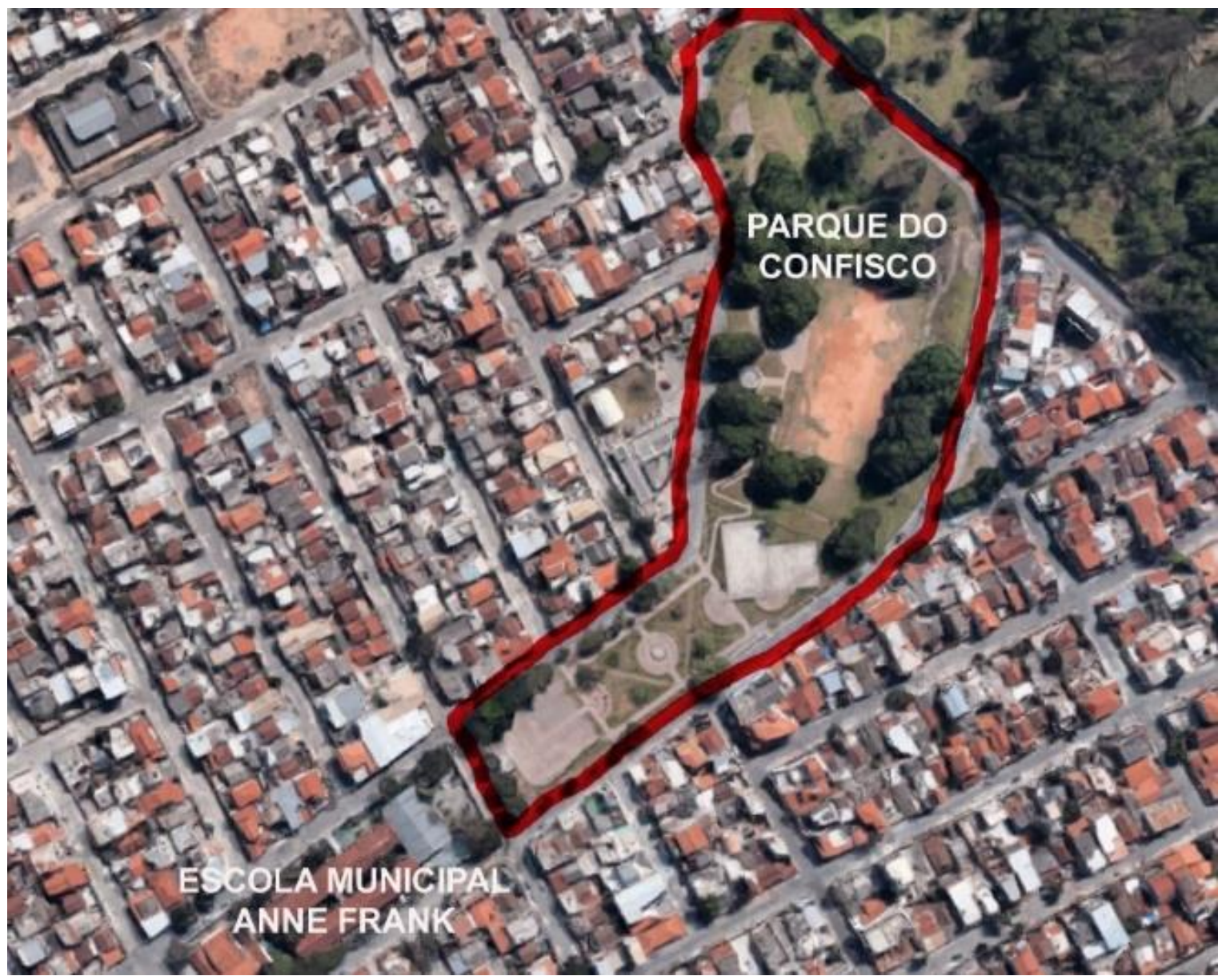

Fonte: Edição das autoras sobre mapa Google Maps (2020).

A Figura 1 revela que o parque está inserido em região densamente habitada e encontra-se contíguo à Escola Municipal Anne Frank. Na parte superior direita da Figura 1 é possível notar área verde, a qual integra o Jardim Zoológico da Fundação de Parque Municipais e Zoobotânica de Belo Horizonte. Convém notar que não existe integração física entre o Jardim Zoológico e o Parque do Confisco. No entorno do parque existem também pontos de ônibus e estabelecimentos comerciais (drogaria, padaria, restaurante, etc.). 
Figura 2 - Elementos do Parque do Confisco.

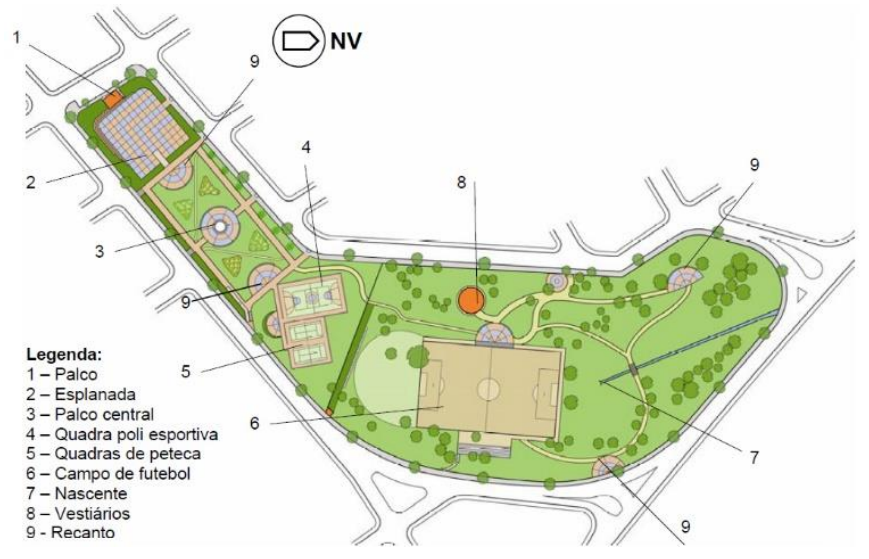

Fonte: Teixeira, 2007.

Conforme mostra a Figura 2, 0 parque foi dividido em três grandes áreas: uma região de preservação ambiental, uma área destinada aos esportes e outra área para contemplação e eventos em geral. Nos locais destinados à preservação, há trilhas, nascentes de água e vegetação densa nativa. Por sua vez, a área destinada aos esportes contém campo de futebol com arquibancadas, quadras de peteca e quadra poliesportiva. Por fim, a terceira área, chamada de praça pela população, possui recantos, palcos e esplanada (TEIXEIRA, 2007).

Atualmente, a área denominada Praça do Confisco (região superior esquerda da Figura 2) bem como a região das quadras de peteca e poliesportiva não apresentam fechamento, apenas guarda-corpo em locais de desnível, podendo ser utilizada pela população em qualquer horário. Contudo, a grande área verde que contém o campo de futebol possui alambrado em todo o seu perímetro, oferecendo oportunidade de restrição do acesso da população. Além disso, antes da pandemia da COVID-19, o campo de futebol do parque era utilizado por uma escola de futebol do bairro, a qual, por meio de voluntários, proporcionava às crianças momentos de lazer e oportunidade de prática de esportes. No recanto entre a esplanada e o palco central (Figura 2) foram instalados equipamentos de ginástica para uso da população. No gramado contíguo a essa área foi instalado playground. A área é bastante frequentada por crianças, que, curiosamente, preferem brincar nos equipamentos de ginástica, em detrimento do playground.

Segundo Teixeira (2007), o terreno destinava-se a abrigar o parque na época do assentamento de famílias no Conjunto Habitacional Confisco. Todavia, o local foi utilizado, durante 
muito tempo, para descarte de terra resultante da obra de um hipermercado na região. Conforme a Prefeitura Municipal de Belo Horizonte, o parque (2019) foi implantado em 1999, com recursos do orçamento participativo.

O orçamento participativo é um importante instrumento de complementação da democracia representativa, pois permite que o cidadão debata e defina os destinos de uma cidade. Nele, a população decide as prioridades de investimentos em obras e serviços a serem realizados a cada ano, com os recursos do orçamento da prefeitura. Além disso, ele estimula o exercício da cidadania, o compromisso da população com o bem público e a corresponsabilização entre governo e sociedade sobre a gestão da cidade (MINISTÉRIO DA ECONOMIA, PLANEJAMENTO, DESENVOLVIMENTO E GESTÃO, 2015, s/p.)

\section{RESULTADOS}

Com relação ao controle natural de acesso, foram identificadas áreas depredadas próximas ao campo de futebol (Figura 3), sendo que, tanto as arquibancadas, quanto os vestiários apresentam pichações. Tais intervenções comprometem a segurança, pois reforçam a desordem percebida, em consonância com Lima Neto e Vieira (2014) e Bondaruk (2007). Contudo, é preciso realizar uma investigação mais profunda sobre tais ocorrências, seus autores e motivações. Caso tenham sido executadas por pessoas da comunidade, existe a possibilidade inserir tais infratores em projetos sociais de caráter artístico, convertendo o desejo de depredação em valorização simbólica do lugar, por meio da arte. Tal sugestão está em conformidade com o conceito de ambiente proposto por Campos-de-Carvalho, Cavalcante e Nóbrega (2011), citado anteriormente. Segundo as autoras, o espaço físico é indissociável das condições sociais.

Figura 3 - Pichações na arquibancada do campo de futebol.

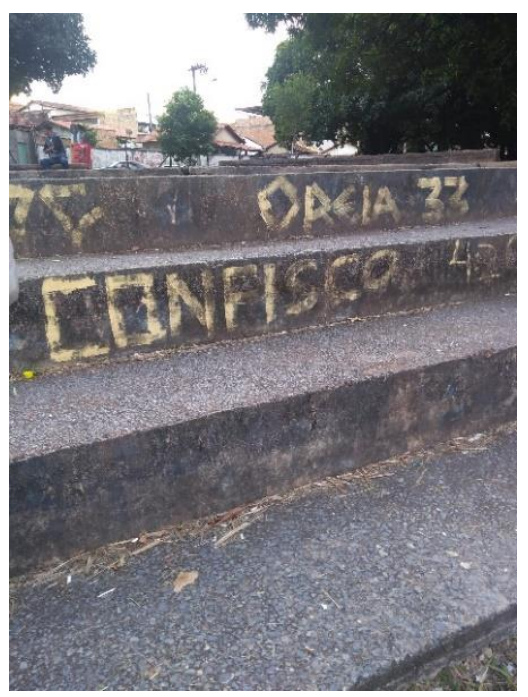

Fonte: Acervo das autoras (2019). 
No tocante à vigilância natural, analisou-se a iluminação artificial, tomando-se por parâmetro os conceitos e recomendações presentes em Jacobs (2011), Crowe (2013) e Bondaruk (2007). As Figuras 4 e 5 revelam incompatibilidade entre iluminação e vegetação, uma vez que a folhagem densa próxima ao ponto de luz diminui a intensidade e a área iluminada no nível dos usuários. A iluminação artificial adequada é imprescindível para a prevenção de crimes à noite, uma vez que a possibilidade de ser visto, por diversos ângulos, reduz a confiança do potencial delinquente. Porém, conforme destacou Jacobs (2011), uma boa iluminação não basta. É preciso que a comunidade desenvolva um comportamento ativo voltado para a prevenção do crime. Além disso, a iluminação deve ser estrategicamente projetada, revelando prováveis locais de esconderijo, bem como conferindo segurança e conforto aos usuários em suas atividades.

Figura 4 - Luminária encoberta por folhas em poste de iluminação pública.

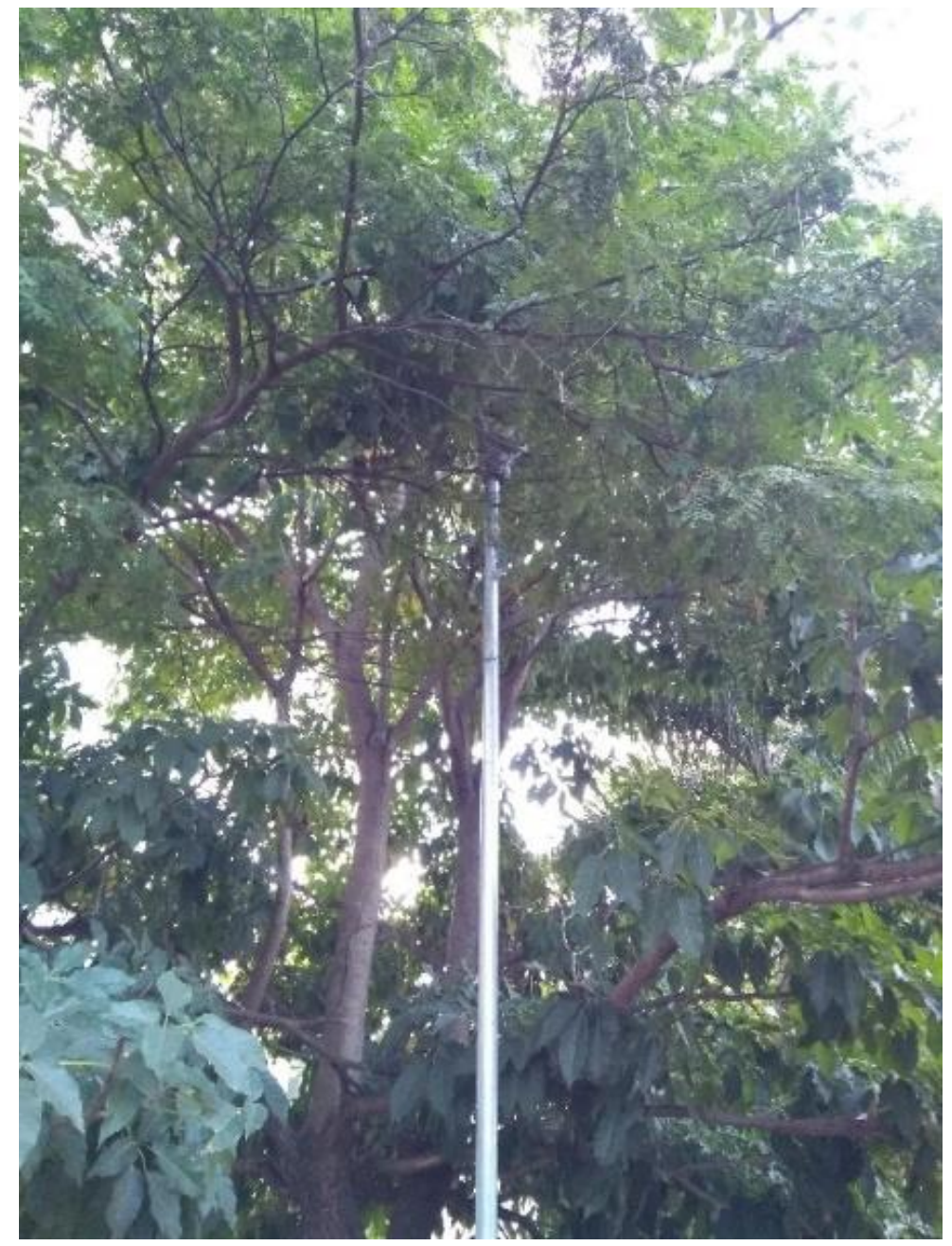

Fonte: Acervo das autoras (2019). 
Figura 5 - Excesso de vegetação ao redor do ponto de luz reduz a área de iluminação.

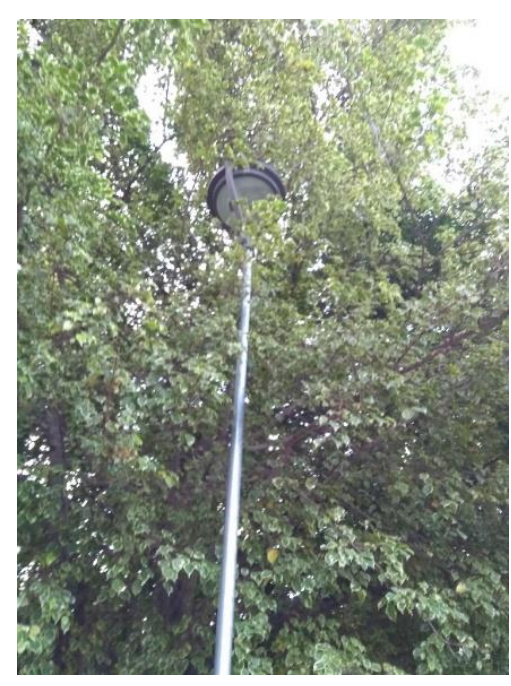

Fonte: Acervo das autoras (2019).

Para análise dos caminhos de pedestres, foram consideradas as recomendações de Bondaruk (2007) para calçadas e praças públicas. A observação revelou que as passagens de pedestres do Parque do Confisco não estão devidamente niveladas e pavimentadas (Figura 6). Logo, na configuração atual, os caminhos não oferecem conforto nem acessibilidade a pessoas com mobilidade reduzida. Dessa forma, reduz-se a quantidade de pessoas que passam por ali, reduzindo-se a vigilância natural.

Figura 6 - Caminhos de pedestres do Parque do Confisco.

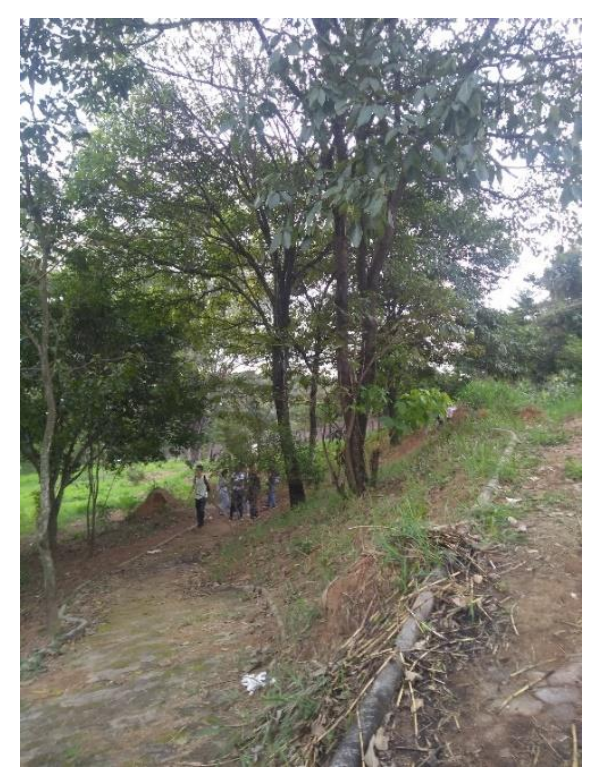

Fonte: Acervo das autoras (2019). 
Além disso, a Figura 6 mostra que o desnível do terreno conjugado ao formato do caminho reduz a visibilidade. O formato sinuoso da área de passagem associado ao talude superior (lado direito da Figura 6) dificulta a visualização do final do percurso, gerando oportunidades para eventuais delinquentes surpreenderem suas vítimas. Conforme Crowe (2013), deve-se facilitar a observação para garantir a vigilância natural. Um bom design de caminhos também deve ser conjugado a um adequado projeto luminotécnico, de modo a tornar os percursos não apenas seguros, mas também, atraentes. Projetos de iluminação com efeito cênico, luzes de diferentes cores e intervenções artísticas ao longo do percurso poderiam contribuir nesse sentido, tornado os caminhos mais convidativos para a população.

A obstrução da visibilidade provocada pela copa das árvores pode ser identificada na Figura 7. Em virtude de seu posicionamento e de sua morfologia (copa muito densa), essas espécies dificultam a visão do campo de futebol por quem passa no nível superior. É notável a intenção de gerar sombra sobre as arquibancadas, contudo, tal necessidade poderia ser compatibilizada com a geração de mais pontos de observação do campo de futebol. Em consonância com Crowe (2013), pode-se inferir que favorecer a vigilância natural implica em fornecer diversos pontos para observação (visadas) de um determinado local. Ao manter potenciais infratores sob observação, pretende-se gerar insegurança nos mesmos, desestimulando, dessa forma, a prática criminosa. Tal estratégia não prejudica os demais usuários, pois a multiplicidade de visadas ofereceria a eles, um aspecto positivo: a variedade de locais para contemplação. Tal conclusão baseia-se em Kuhnen e Higuchi (2011). As autoras afirmam que a percepção ambiental está relacionada com a maneira pela qual cada pessoa experimenta os espaços que utiliza.

Figura 7 - Campo de futebol da Parque do Confisco.

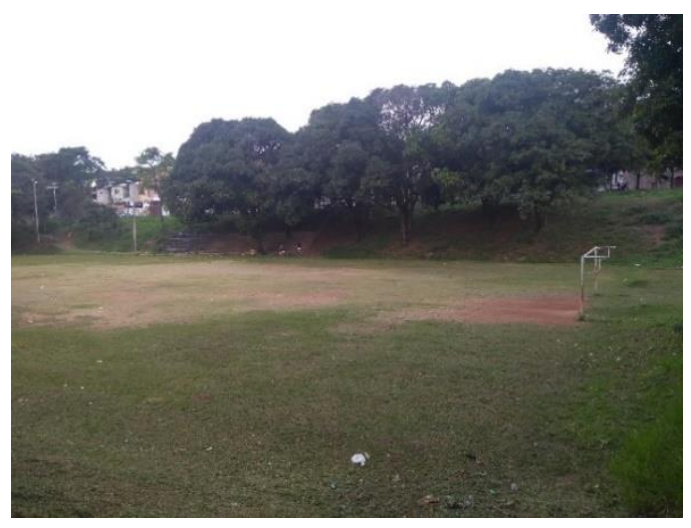

Fonte: Acervo das autoras (2019). 
Por outro lado, o campo de futebol (Figura 7) contribui com reforço territorial, haja vista que existe certa harmonia entre o uso proposto, o design e o uso real. Conforme mencionado anteriormente, o campo era utilizado por uma escola de futebol do bairro, a qual, por meio de voluntários, proporcionava às crianças um momento de lazer e oportunidade de prática de esportes. Tal uso favorecia a criação de relações de pertencimento entre o parque e a comunidade. Iniciativas como essa tem potencial para reunir e estimular a convivência entre as pessoas, criando laços de amizade e cooperação. O fato de existir arquibancadas também é um fator que contribui para o uso do local por diversos públicos e não somente pelos desportistas. Todavia, nota-se que o campo requer manutenção mais frequente e efetiva, necessidade recorrente em outras áreas do parque. A importância da apropriação territorial dos espaços pela comunidade foi anteriormente destacada por Crowe (2013) e Bondaruk (2007).

No entanto, o acúmulo de lixo próximo à área das arquibancadas (Figura 8) indica que ainda há o que melhorar no quesito reforço territorial. Convém notar também a escassez de lixeiras no entorno do campo, o que favorece, embora não determine, o descarte em locais impróprios. Além disso, a observação das embalagens descartadas no local revelou que algumas estão fora de uso no mercado, dando indícios da deficiente coleta de resíduos sólidos, isto é, da falta de manutenção. Conforme Crowe (2013), Bondaruk (2007) e Lima Neto e Vieira (2014), a falta de manutenção implica na imagem de abandono, gerando a desordem percebida, a qual é fomentadora de ações criminosas. Embora seja necessária, a instalação de lixeiras não é suficiente. É preciso um trabalho de conscientização da população, trabalho esse voltado para a construção do senso responsabilidade das pessoas com relação aos espaços, conforme recomenda Crowe (2013). Considerando o conceito de ambiente apresentado por Campos-de-Carvalho, Cavalcante e Nóbrega (2011), é preciso pensar as soluções que integrem tanto o aspecto físico quanto a dimensão humana dos ambientes. 
Figura 8 - Acúmulo de lixo próximo à arquibancada do campo de futebol.

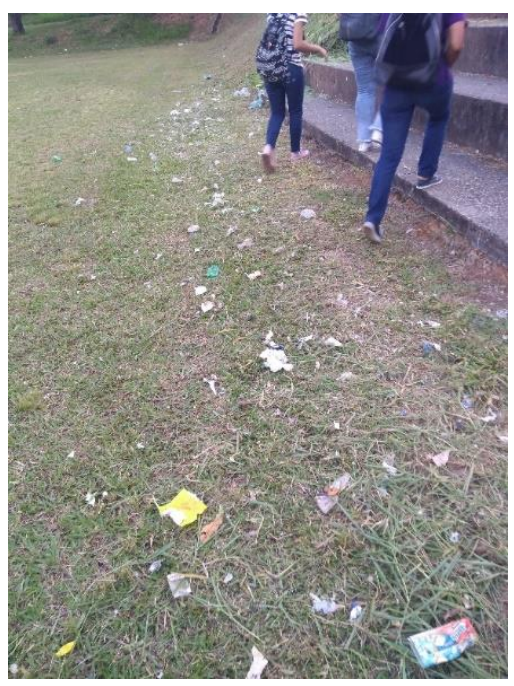

Fonte: Acervo das autoras (2019).

Além do campo de futebol, a academia ao ar livre apresenta aspectos capazes de contribuir para o reforço territorial. Localizada no recanto entre a arena e o palco central (Figura 2), a academia ao ar livre está em bom estado de conservação e pode ser observada por diversos pontos a partir da rua superior (Figura 9). Ademais, a proximidade entre a academia ao ar livre e o playground (Figura 9) favorece a convivência de públicos de diferentes idades, bem como facilita a vigilância das crianças pelos responsáveis. Porém, o apelo lúdico da área da recreação infantil requer melhorias, pois notou-se que as crianças preferiam brincar na academia ao ar livre. A proximidade com a Escola Municipal Anne Frank (Figura 1) também poderia ser melhor explorada, utilizando a área do parque para atividades pedagógicas, de modo a fortalecer as relações de pertencimento entre a comunidade e o local. Segundo Bondaruk (2007), a criação de tais relações de pertencimento é fundamental para a manutenção da segurança.

Figura 9 - Playground e academia ao ar livre.

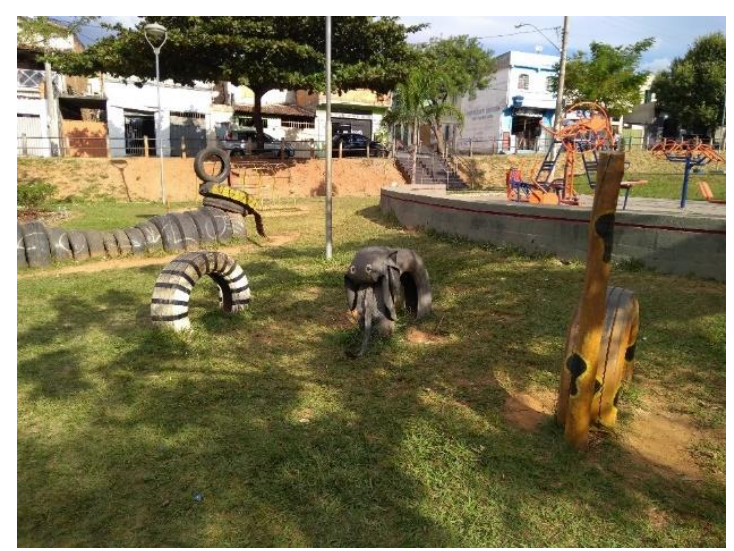

Fonte: Acervo das autoras (2019). 
Em que pese todas as potencialidades identificadas no quesito apropriação territorial, não foram encontrados marcos simbólicos expressivos que denotem uma forte relação de pertencimento do parque em relação à comunidade. Embora tal relação possa existir, como não há marcos espaciais significativos, não está claramente determinado "quem é o dono" do espaço, o que pode estimular a noção de desordem percebida.

A análise espacial revelou que é possível remover os fatores que favorecem a prática criminosa, contudo é necessário o desenvolvimento de projetos integrados. Por um lado, é necessário proceder a alterações físicas, como modificação da pavimentação dos caminhos, mudança na disposição da vegetação, etc. Por outro lado, também é preciso construir e/ou estimular o senso de responsabilidade da comunidade em relação ao espaço. Tal estímulo deve ser feito por meio de projetos de ressignificação espacial, de modo que a população fortaleça os laços de pertencimento com o parque e converta tais sentimentos em atitudes de conservação e vigilância. Ademais, recomenda-se que tais projetos sejam integrados e participativos, de modo a potencializar os seus efeitos.

Convém lembrar que o Parque do Confisco foi implantado por um processo de gestão participativa, o que revela certo grau de organização e engajamento comunitário. Portanto, é possível inferir que existe no bairro potencial para implementação de projetos participativos. Portanto, o Parque do Confisco é um local oportuno para desenvolvimento de projetos com base no CPTED, resultando em um local seguro, valorizado e cuidado pela população local.

A importância deste trabalho reside em fornecer as bases para o desenvolvimento de pesquisas mais profundas sobre o tema. O estudo destaca os elementos físicos a considerar, bem como a maneira pela qual esses se relacionam com os aspectos comportamentais. Portanto, o espaço físico deve ser entendido em sua relação com o comportamento humano, no intuito de reforçar ações desejáveis por parte da comunidade e inibir ações criminosas.

\section{CONSIDERAÇÕES FINAIS}

O Parque do Confisco, espaço público construído por meio do engajamento da comunidade local, tem em sua história momentos de dificuldade e superação, marcados por pessoas que lutaram por direitos, em prol da melhoria da qualidade de vida de todos. Embora símbolo 
importante de conquistas comunitárias, o local requer ações no intuito de reforçar a apropriação territorial e fortalecer a cidadania, com consequente impacto positivo na prevenção de crimes.

Contrariando o senso comum, os princípios do CPTED mostram que, viver em ambientes mais seguros não requer opressão, hostilidade ou retraimento social. Pelo contrário, a prevenção do crime não prescinde do fortalecimento da cidadania, da apropriação dos espaços, da criação de relações de pertencimento entre pessoas e ambientes, bem como do cuidado e da responsabilidade das pessoas com as áreas públicas que utilizam.

Portanto, divulgar as estratégias de prevenção do crime por meio do design é de extrema importância para um país, que não por coincidência, apresenta desigualdade social e criminalidade alarmantes. Fortalecer ações comunitárias, com o devido apoio teórico-metodológico da academia, é fundamental para a geração de ambientes mais seguros e socialmente mais inclusivos, capazes de promover a qualidade de vida das pessoas.

Esta pesquisa, por possuir caráter exploratório, dedicou-se a estimular outras pesquisas sobre o tema. Foram definidas relações prévias entre o espaço físico e o comportamento humano. No entanto, o advento da pandemia da COVID-19, a qual impôs a necessidade de isolamento social, impediu uma investigação profunda sobre os usuários do Parque do Confisco. Logo, foram necessárias simplificações no método escolhido, a abordagem 3D, proposta por Crowe (2013), uma vez que a mesma não dispensa à(o) pesquisador(a) o contato com a comunidade. Ademais, entende-se que qualquer investigação de caráter social, no contexto atual de pandemia, poderia produzir resultados artificiais, haja vista que o isolamento foi imposto pelos governos, alterando, forçadamente, o uso corriqueiro dos espaços. Portanto, para trabalhos futuros, recomenda-se o aprofundamento nas investigações sobre a relação espaço-usuário, bem como a aplicação abrangente da abordagem 3D.

\section{REFERÊNCIAS}

AMARO, M. A. Arquitetura contra o crime: prevenção do crime através da arquitetura ambiental. Rio de Janeiro: [s.n.], 2005.

AMORIM, L. M. R. Criminalidade em Belo Horizonte: uma análise sobre seus aspectos temporais e espaciais e discussão dos efeitos das bases móveis da Polícia Militar sobre sua dinâmica. 2018. Monografia (Graduação em Administração Pública) - Escola de Governo Professor Paulo Neves de 
Carvalho, Fundação João Pinheiro, Belo Horizonte, 2018. Disponível em:

http://monografias.fjp.mg.gov.br/handle/123456789/2529. Acesso em: 6 jan. 2021.

BONDARUK, R. L. A prevenção do crime através do desenho urbano. Curitiba: Edição do autor, 2007.

CAMPOS-DE-CARVALHO, M. I.; CAVALCANTE, S.; NÓBREGA, L. M. A. Ambiente. In: CAVALCANTE, S.; ELALI, G. (org.) Temas Básicos em Psicologia Ambiental. Petrópolis: Vozes, 2011. p.28-41.

CLARKE, R. V. Situational Crime Prevention: successful case studies. 2. ed. New York: Harrow and Heston Publishers, 1997.

CLARKE, R. V. Regulation Crime: The Birth of the Ideia, Its Nurture and the Implications for Contemporary Criminology. The ANNALS of the American Academic of Political and Social Science, United Kingdom, v. 679, n. 1, p. 20-35, 2018. https://doi.org/10.1177/0002716218775031.

Disponível em: https://journals.sagepub.com/doi/abs/10.1177/0002716218775031 . Acesso em: 26 jan.2020.

CROWE, T. D. Crime Prevention Through Environmental Design. Revisado por Lawrence J. Fennelly. 3. ed. Oxford: Butterworth-Heinemann, 2013.

FERREIRA, E. L. T.; DAMÁZIO, I. N.; AGUIAR, J. M. de. Fatores estimuladores da sensação de insegurança e valorização midiática. Revista Ordem Pública e Defesa Social, Florianópolis, v. 4, n. 1, p. 121-130, semestre I e II, 2011. Disponível em: https://rop.emnuvens.com.br/rop/article/view/41. Acesso em: 10 dez. 2020.

FUNDAÇÃO JOÃO PINHEIRO. Informativo FJP: indicadores sociais IMRS segurança pública. Belo Horizonte: Fundação João Pinheiro, n. 5, 2019. Disponível em:

http://www.bibliotecadigital.mg.gov.br/consulta/consultaDetalheDocumento.php?iCodDocumento =57235. Acesso em: 6 jan. 2021.

GIL, A. C. Como elaborar projetos de pesquisa. 4. ed. São Paulo: Atlas, 2002.

JACOBS, J. Morte e vida de grandes cidades. 3. ed. São Paulo: Martins Fontes, 2011.

KUHEN, K.; HIGUCHI, M.I.G. Percepção Ambiental. In: CAVALCANTE, S.; ELALI, G. (org.) Temas Básicos em Psicologia Ambiental. Petrópolis: Vozes, 2011. p.250-266.

LIMA NETO, J. S. de L.; VIEIRA, T. A. A estratégia de prevenção do crime através do desenho urbano. Revista Ordem Pública e Defesa Social, v.7, n. 1, p. 55-77, 2014. Disponível em: https://rop.emnuvens.com.br/rop/article/view/67. Acesso em: 6 de junho de 2019.

LYNCH, K. A imagem da cidade. São Paulo: Martins Fontes, 1999. 
MCCLAIN, J. Distinguished Faculty Member Dr. Ronald Clarke Wins Prestigious Stockholm Prize in Criminology. Rutgers University- Newark, 5 nov. 2014. Disponível em:

https://www.newark.rutgers.edu/news/distinguished-faculty-member-dr-ronald-clarke-winsprestigious-stockholm-prize-criminology. Acesso em: 10 jan. 2021.

MINISTÉRIO DA ECONOMIA, PLANEJAMENTO, DESENVOLVIMENTO E GESTÃO. O que é orçamento participativo? , 2015. Disponível em: http://www.planejamento.gov.br/servicos/faq/orcamentoda-uniao/elaboracao-e-execucao-do-orcamento/o-que-e-orcamento-participativo . Acesso em: 14 mar. 2020.

NAPOLEÃO JÚNIOR, E. C.; SILVEIRA, M. A. A estratégia da prevenção do crime e da desordem através do desenho urbano: realidade do estádio de futebol Orlando Scarpelli. Revista Ordem Pública e Defesa Social, Florianópolis, v. 10, n. 1, p. 33-52, jan./jul., 2018. Disponível em: https://rop.emnuvens.com.br/rop/article/view/145. Acesso em: 10 dez. 2020.

NATIONAL INSTITUTE OF CRIME PREVENTION. CPTED Trainning. 2021. Disponível em: https://www.cptedtraining.net/.Acesso em: 4 jan. 2021.

PARQUE do Confisco - Rua G - Conjunto Confisco, Belo Horizonte - MG. In: GOOGLE Maps. Mountain View: Google, 2020. Disponível em: https://goo.gl/maps/DzHFsNxK8F7CmTHh8 . Acesso em: 5 de mar. 2020

PERRY, M. Foreword. In: CROWE, T.D. Crime Prevention Through Environmental Design. Revisado por Lawrence J. Fennelly. 3 ed. Oxford: Butterworth-Heinemann, 2013.

PREFEITURA MUNICIPAL DE BELO HORIZONTE. Parque do Confisco. 2019. Disponível em: https://prefeitura.pbh.gov.br/fundacao-de-parques-e-zoobotanica/informacoes/parques/parquedo-confisco . Acesso em: 14 mar. 2020.

REVISTA ORDEM PÚBLICA E DEFESA SOCIAL. Florianópolis: Associação dos oficiais militares de Santa Catarina. 2008-. ISSN: 223-6380 versão online. Disponível em: https://rop.emnuvens.com.br/rop. Acesso em: $10 \mathrm{dez} .2020$.

TEIXEIRA, R. S. Análise da Apropriação pelos Usuários de Parques Urbanos: Estudo de Caso na Bacia da Pampulha - Belo Horizonte, MG. Dissertação (Mestrado em em Ciência Florestal ), Universidade Federal de Viçosa, Viçosa, 2007. Disponível em: https://www.locus.ufv.br/handle/123456789/3185. Acesso em: 13 mar. 2020.

TILLEY, N.; FARRELL, G (org.). The Reasoning Criminologist: Essays in Honour of Ronald V. Clarke. New York: Routledge, 2012. 